\title{
RISCOS DECORRENTES DA REPRODUTIBILIDADE DA AGRICULTURA CONVENCIONAL POR AGRICULTORES FAMILIARES, EM JAGUARUANA - CE, BRASIL
}

\author{
Washington da Silva Bernardoㄹ; Janne Kleia da Silva²; João Joel de Oliveira Neto³ \\ Carlos Vangerre de Almeida Maia ${ }^{1}$
}

${ }_{1}^{1}$ Professor do Instituto Centro de Ensino Tecnológico (CENTEC)/EEEP Francisca Rocha Silva - Jaguaruana - Ceará - Brasil. (wbernardo@live.com).

2 Professora na Rede Municipal de Ensino de Jaguaruana - CE / Secretaria

Municipal de Educação de Jaguaruana - Ceará - Brasil.

${ }^{3}$ Professor da Rede Estadual de Ensino do Ceará/EEEP Francisca Rocha Silva Jaguaruana - Ceará - Brasil.

Recebido em: 02/10/2017 - Aprovado em: 21/11/2017 - Publicado em: 05/12/2017 DOI: 10.18677/EnciBio_2017B61

\begin{abstract}
RESUMO
As inovações tecnológicas pontuadas na agricultura brasileira, a partir de 1960, providas na tecnificação e utilização expressiva de insumos industriais atenderam, a priori, os interesses da agroindústria com base no capital internacional e apoio estatal. Ao segmento da agricultura familiar, com a lógica da pequena produção, o Estado passa a conceder minimamente o crédito rural, com o critério de concessão de parte desse recurso para a aquisição de agrotóxicos. Surgindo a reprodutibilidade da agricultura química e suas implicações para a agricultura familiar. A pesquisa ocorreu mediante aplicação de questionários a agricultores filiados ao Sindicato dos Trabalhadores Rurais, Agricultores e Agricultoras Familiares de Jaguaruana. Constatou-se que os agrotóxicos são adquiridos em estabelecimentos não recomendados, predominância de policultura, mínima utilização de Equipamentos de Proteção Individual (EPIs), débil assistência técnica e descarte de embalagens feita de maneira inadequada, apontando fragilidade na fiscalização por parte dos órgãos responsáveis e pondo em xeque a máxima do uso seguro dos agrotóxicos.
\end{abstract}

PALAVRAS -CHAVE: Agricultura Familiar. Agrotóxico. Logística Reversa.

\section{RISKS DUE TO REPRODUCIBILITY OF CONVENTIONAL AGRICULTURE BY FAMILY FARMERS IN JAGUARUANA - CE, BRAZIL}

\section{ABSTRACT}

Technological innovations punctuated in Brazilian agriculture since 1960, provided in the technification and expressive use of industrial inputs, a priori, addressed the interests of agroindustry based on international capital and state support. To the segment of family agriculture, with the logic of small production, the State starts to grant rural credit minimally, with the criterion of granting part of this resource for the acquisition of agrochemicals. Raising the reproducibility of chemical agriculture and its implications for family agriculture. The research was developed through application of questionnaires to union farmers with the Union of Rural Workers, 
Farmers and Family Farmers from Jaguaruana, Ceará, Brazil. It was found that agrochemicals are purchased in non-recommended establishments, predominance of polyculture, minimal use of Personal Protective Equipment (PPE), weak technical assistance and improperly disposed of packaging, pointing out fragility in the inspection by the responsible institutions and putting in question the maximum about the safe use of agrochemicals.

KEYWORDS: Family farming. Agrochemical. Reverse logistic.

\section{INTRODUÇÃO}

A agricultura familiar foi definida pela Lei Federal $n^{\circ} 11.326$ de 24 de julho de 2006 como aquela que atende aos seguintes critérios para tal: a área do estabelecimento ou empreendimento rural não excede quatro módulos fiscais; a mão-de-obra utilizada nas atividades econômicas é predominantemente da própria família; a renda familiar seja oriunda das atividades vinculadas ao próprio estabelecimento; o estabelecimento ou empreendimento é dirigido pela família (BRASIL, 2006).

O debate sobre a agricultura familiar no capitalismo não é um tema novo. Ganhando força a partir do final dos anos 1980 e início dos anos 1990. Na literatura, as discussões se voltam para a permanência, ou não, dessa forma de produção, com o desenvolvimento das relações capitalistas no campo. Outros procuram entender o seu modo de funcionamento, bem como a sua integração no sistema social e econômico dominante (PLEIN, 2010).

Historicamente, a agricultura familiar ou os pequenos agricultores - como eram denominados até cerca de duas décadas atrás - sempre estiveram às margens das ações do Estado brasileiro, não raro incrementando sua fragilidade diante das opções de desenvolvimento perseguidas pelo País, onde, em pleno século XXI, é possível constatar que esse modelo tem poucos incentivos estatais, limitações na posse da terra, na assistência técnica e na participação no mercado (GRISA; SCHNEIDER, 2014).

Essa constatação fica muito evidente pela opção do Estado brasileiro por uma modernização conservadora da agricultura, que privilegiou as mudanças tecnológicas em detrimento de uma alteração na estrutura fundiária do país na segunda metade do século XX (PLEIN; FILIPPI, 2011).

O Brasil iniciou seu processo de industrialização no meio rural, através da modernização da agricultura, a qual tinha por base um modelo de produção agrícola sustentado por pacotes tecnológicos. Este congregava às inovações tecnológicas, o aumento da produtividade mediante o uso intensivo de insumos químicos, de variedades de alto rendimento, melhoradas geneticamente, da irrigação e da mecanização, da utilização de mão de obra barata, entre outras estratégias voltadas à produção agrícola. Dessa forma, propagou-se, na década de 1960, no meio rural, a crença de que ser moderno era um valor a ser perseguido (ALMEIDA, 2011).

Os principais instrumentos que viabilizaram o novo modelo agrícola, foram calcados na tecnificação, utilização maciça de insumos industriais, no aumento da exportação de produtos agrícolas que, consequentemente, ocasionaram a transformação da sociedade rural nos últimos anos. O crédito rural, concedido minimamente aos agricultores familiares, trouxe uma base empírica de experimentação, através do incentivo aos agrotóxicos (SOCOLOSKI et al., 2016).

Para Brasil (2002), agrotóxicos são produtos e agentes de processos físicos, químicos ou biológicos, destinados ao uso nos setores de produção, no armazenamento e beneficiamento de produtos agrícolas, nas pastagens, na 
proteção de florestas, nativas ou plantadas, e de outros ecossistemas e de ambientes urbanos, hídricos e industriais, cuja finalidade seja alterar a composição da flora ou da fauna, a fim de preservá-las da ação danosa de seres vivos considerados nocivos, bem como as substâncias e produtos empregados como desfolhantes, dessecantes, estimuladores e inibidores de crescimento.

Desde 2009, o Brasil é o maior consumidor de agrotóxicos do mundo, país onde circulam mais de 300 princípios ativos e 2000 formulações diferentes e onde se estima que cada habitante consome, em média, $5,2 \mathrm{Kg}$ de agrotóxico por ano (CARNEIRO et al, 2015).

A literatura aponta costumeiro hábito de pequenos agricultores utilizando esses produtos de maneira indiscriminada, cujas deficiências vão desde a aquisição do produto ao descarte dos vasilhames, trazendo impactos a saúde humana e ao meio ambiente (SANTOS et al., 2013; SILVA et al., 2014; SOCOLOSKI et al., 2016).

Portanto, o objetivo deste trabalho é investigar a cadeia da utilização desses insumos por parte dos pequenos agricultores, onde, para esse estudo, foram entrevistados agricultores do município de Jaguaruana-CE, Brasil.

\section{MATERIAL E MÉTODOS}

O estudo é do tipo descritivo, cuja pesquisa foi realizada junto à produtores rurais do município de Jaguaruana - CE, Brasil (Figura 1), situado na região do Litoral Leste cearense, distante, aproximadamente $210 \mathrm{~km}$ ao sudeste de Fortaleza.
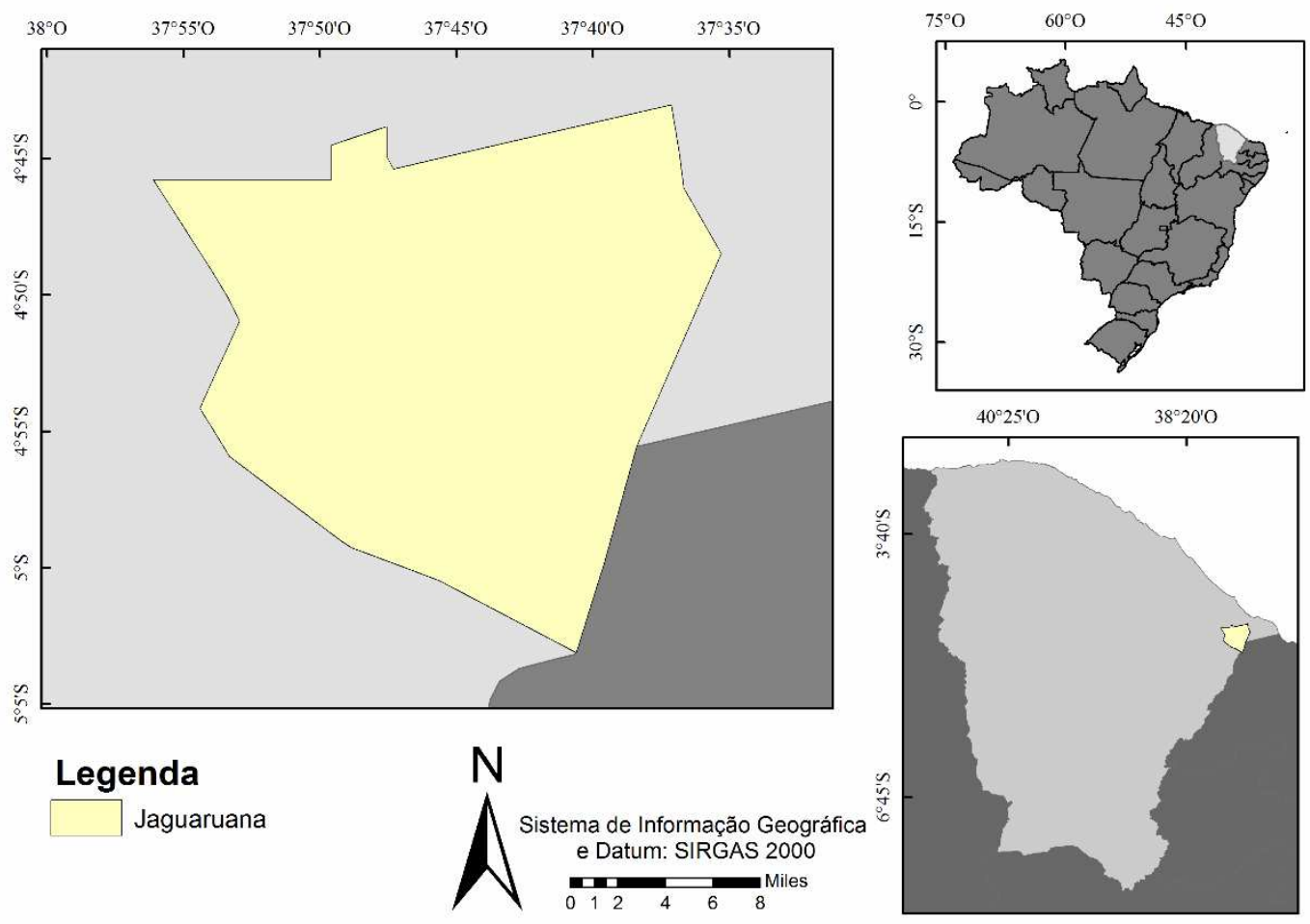

FIGURA 1 - Mapa de localização do município de Jaguaruana - CE, Brasil. Fonte: os autores.

A amostra foi baseada em seleção aleatória, onde participaram 48 agricultores, cujos critérios de elegibilidade foi sua filiação ao Sindicato dos Trabalhadores Rurais, Agricultores e Agricultoras Familiares de Jaguaruana, cadastro em algum programa de política pública do setor, confirmado pela Secretaria 
Municipal de Agricultura, aos quais, individualmente, foi aplicado um questionário semiestruturado, no segundo trimestre do ano de 2017.

As questões abordadas se remetiam a perfil etário, modo de aquisição dos agroquímicos, utilização de EPIs, risco e descarte dos vasilhames, cujos dados foram organizados em uma planilha eletrônica do Microsoft Office Exce ${ }^{\circledR}$, tabulados e apresentados por meio de estatística descritiva.

\section{RESULTADOS E DISCUSSÕES}

Dos entrevistados, predominou indivíduos do gênero masculino (54,2\%), com faixa etária entre 51 e 60 anos de idade (35,4\%), sendo interessante frisar a baixa frequência de indivíduos com faixa etária entre 18 a 30 anos, conforme apresenta a Tabela 1.

TABELA 1: Faixa etária dos agricultores investigados.

\begin{tabular}{lrr}
\hline \hline \multicolumn{1}{c}{ Faixa Etária } & Frequência & \multicolumn{1}{c}{$\%$} \\
\hline 18 a 30 anos & 3 & 6.3 \\
31 a 40 anos & 12 & 25.0 \\
41 a 50 anos & 9 & 18.8 \\
51 a 60 anos & 17 & 35.4 \\
Acima de 60 anos & 7 & 14.6 \\
Total & 48 & 100.0 \\
\hline \hline
\end{tabular}

Fonte: os autores.

A baixa frequência de indivíduos mais jovens, quando comparados a indivíduos mais idosos também ocorreu na pesquisa de Cajaiba et al. (2015), cuja repetição pode corroborar com a tendência demográfica nacional de recrudescimento da população rural.

Maia e Buainain (2015) apontam que, entre o período intercensitário, de 1990 a 2010, no campo, a população mais jovem (menores de 18 anos) reduziu em cerca de 6,4 milhões de habitantes, havendo estagnação nos indivíduos entre 18 e 64 anos e acréscimo de 0,6 milhões de pessoas mais idosas (65 anos ou mais).

Identificar poucos jovens produtores da agricultura familiar pode ser uma das consequências do processo de desqualificação e inviabilização dessa prática, no sentido de que esta está comprometida, devido à uma série de fatores, indo desde da ausência de políticas públicas e crédito, até mesmo a rentabilidade desta modalidade, pois, não dispondo de recursos materiais para a produção, o agricultor acaba por abandoná-la, vindo a tornar-se um trabalhador de alguma grande empresa agrícola.

A reduzida frequência de jovens no campo Jaguaruanenses (18 - 30 anos) pode provocar uma silenciosa consequência: 0 esquecimento dos saberes tradicionais, em contraste com a adoção de técnicas ligadas ao modelo agroindustrial, como por exemplo, o uso de insumos químicos.

De acordo com Leff (2002), uma das possibilidades para a manutenção e difusão dos saberes tradicionais, é a agroecologia, por sua capacidade de diálogo com as cadeias de produção familiar. Indagados sobre o tipo de cultivo realizado, os 
produtores, em sua maioria $(58,3 \%)$ afirmou cultivar mais de um tipo de cultura (policultura), cuja informação pode ser constatada na Figura 2.

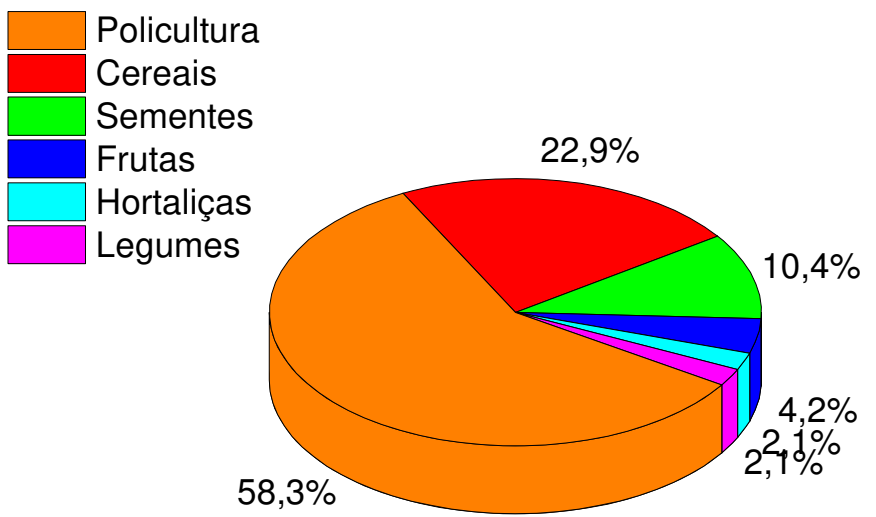

FIGURA 2: Tipos de culturas produzidas

Fonte: os autores.

Constatou-se que os entrevistados priorizam a prática da policultura, que nada mais é do que o cultivo de diversas espécies agrícolas em uma mesma propriedade de forma simultânea ou sequencial temporal. Dentre as práticas monocultoras, por ordem, identificou-se a seguinte sequência: cereais (milho e arroz), sementes (feijão e fava), frutas (banana e goiaba), legumes (batata e cenoura) e hortaliças (coentro e alface).

Sousa et al. (2016), em seu estudo, realizado na cidade de Barro, região do Cariri no Estado do Ceará, verificou que pelo menos $50 \%$ de sua população amostral praticava a policultura de produtos de subsistência como grãos, sementes e cereais, concordando com o constatado em Jaguaruana - $\mathrm{Ce}$ - Brasil.

A policultura mantém o equilíbrio do agrossistema pelo retorno de matéria orgânica ao solo, melhorando sua fertilidade e reduzindo a infestação de pragas, contribuindo para agregar valor aos agroecossistemas familiares, uma vez que trabalha com a reconfiguração de ambientes rurais, através da diversificação de atividades agropecuárias que atendem aos critérios solicitados nas discussões sobre sustentabilidade. Além de complementar a renda dos produtores rurais, e contribuir para a conservação da flora nativa e das demandas de segurança alimentar e nutricional (VITAL et al., 2016).

A policultura, principalmente ocorrendo pelo modelo de cultivo consorciado, é normalmente, mais praticado por pequenos produtores familiares, que produzem tanto para seu próprio sustento quanto para a comercialização (AQUINO; ASSIS, 2017). Porém, a inserção de agrotóxicos na agricultura familiar é algo que pode ser visualizado em outros trabalhos, como o realizado por Silva et al. (2013), na região do Jacuí-Centro, no sul do Brasil.

Entre os entrevistados, essa realidade foi predominantemente constatada, uma vez que $85,4 \%$ dos agricultores afirmaram fazer uso de agrotóxicos, ante $14,6 \%$, que se utilizam de métodos naturais, vide Figura 3. 


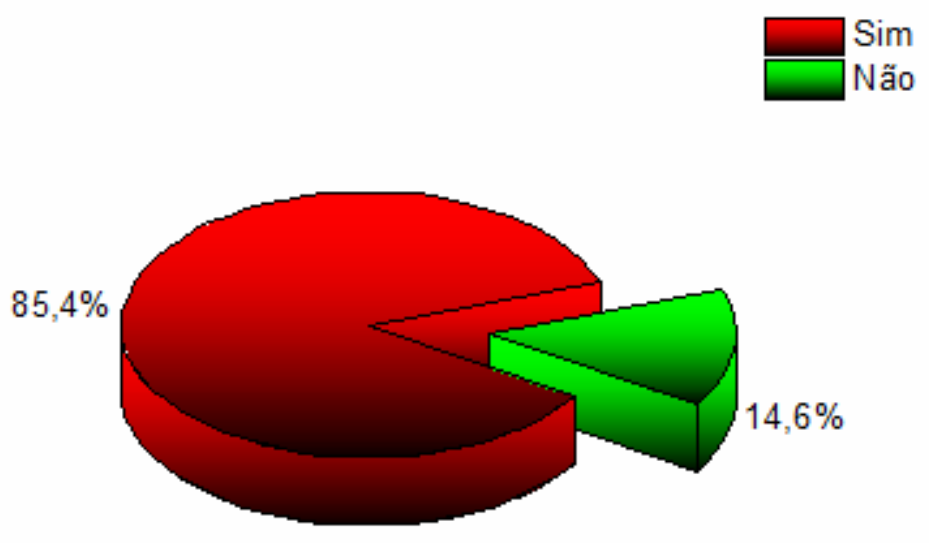

FIGURA 3: Utilização de agrotóxicos por parte de pequenos agricultores, em Jaguaruana - CE, Brasil Fonte: os autores.

Para Sobrinho e Mota (2016), a utilização de defensivos naturais não acarreta nenhum risco ao homem e nem ao meio, pode melhorar a qualidade agrícola e promove sustentabilidade ambiental, mas esse método não possui larga utilização por não conseguir dar resposta a curto prazo, condição que o mercado impõe, para garantir maior produção em menos tempo, de modo que garanta a contínua e crescente demanda por alimentos.

De acordo com Silva et al. (2014), a Norma Regulamentadora $n^{\circ} 31$ do Ministério do Trabalho e Emprego afirma ser vedada a manipulação de qualquer agrotóxico por menores e maiores de 60 anos, o que, mediante a Tabela 2, é possível verificar que $100 \%$ dos sexagenários investigados descumprem esta preconização.

TABELA 2: Utilização de agrotóxicos por faixa etária.

\begin{tabular}{lrrrrrr}
\hline \hline & & \multicolumn{5}{c}{ Faixa etária } \\
\cline { 2 - 7 } & & $\begin{array}{c}18 \text { a } 30 \\
\text { anos }\end{array}$ & $\begin{array}{c}31 \text { a } 40 \\
\text { anos }\end{array}$ & $\begin{array}{c}41 \text { a } 50 \\
\text { ano }\end{array}$ & $\begin{array}{c}51 \text { a } 60 \\
\text { anos }\end{array}$ & $\begin{array}{c}\text { Acima } \\
\text { de } 60 \\
\text { anos }\end{array}$ \\
\hline \multirow{2}{*}{ Uso de Agrotóxicos (\%) } & Sim & 100 & 66.7 & 88.9 & 88.2 & 100 \\
& Não & 0 & 33.3 & 11.1 & 11.8 & 0 \\
\hline \hline
\end{tabular}

Fonte: os autores

A faixa etária pode ser fator de risco, podendo agravar a situação de saúde dos indivíduos expostos aos agroquímicos, principalmente jovens e idosos, que são mais susceptíveis a adoecimento (VASCONCELOS et al., 2014).

Após constatar irregularidade entre os possíveis manipuladores, os agricultores foram questionados sobre onde era feita a aquisição dos agrotóxicos, identificando que $66,7 \%$ dos entrevistados os adquirem em locais inapropriados, como mercadinhos, armazéns ou qualquer outro de estabelecimento comercial, conforme apresentado na Figura 4. 


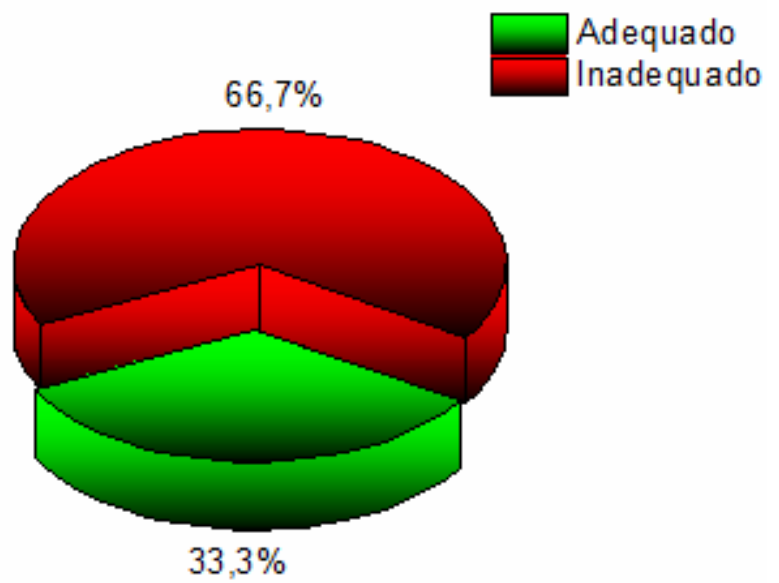

FIGURA 4: Local de aquisição dos agrotóxicos por parte dos pequenos agricultores, em Jaguaruana - CE, Brasil. Fonte: os autores.

Salienta-se que $60,9 \%$ dos usuários de agrotóxicos admitem que costumam não receber nota fiscal do produto, que além de ser um claro caso de sonegação fiscal, incide contra o postulado no Decreto Federal $n^{\circ} 4.074 / 2002$, que condiciona a existência da Nota Fiscal, como elemento determinante para a devolução das embalagens por parte dos compradores, na perspectiva da logística reversa.

A débil e/ou omissa fiscalização na comercialização de agrotóxicos fica evidenciada ao constatar essa prática em locais indevidos e ausência de Nota Fiscal, podendo acarretar em uso deliberado e indevido, promovendo externalidades não contabilizadas, como contaminação do meio, dos alimentos e, por conseguinte, do próprio ser humano.

Resolveu-se averiguar se os respondentes utilizam EPIs durante a aplicação, onde, conforme Figura 5, é notório o desuso desse tipo de equipamento, vide que $70,7 \%$ dos produtores não os utilizam.

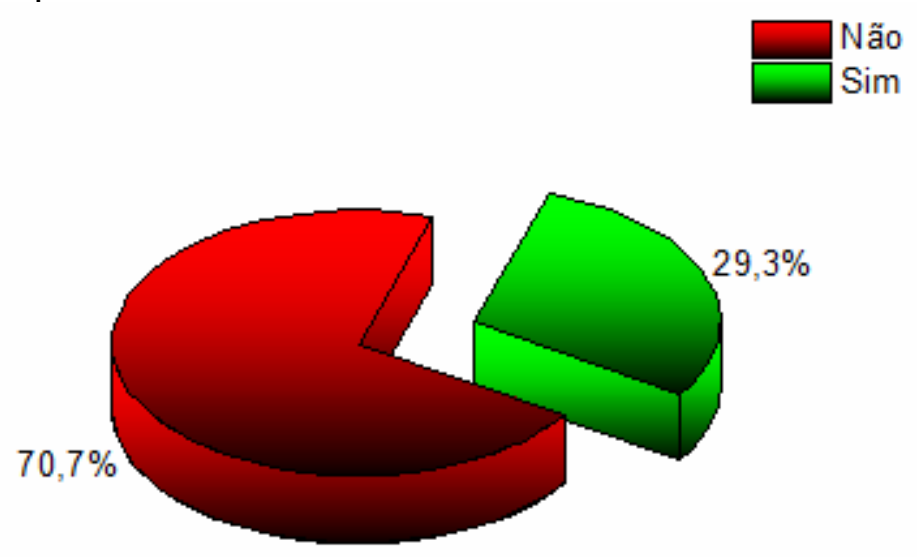

FIGURA 5: Utilização de EPIs por parte dos

agricultores do município de Jaguaruana - CE, Brasil.

Fonte: os autores.

O correto uso de EPIs pode minimizar riscos de intoxicação por parte do manipulador, haja vista que esses insumos agroquímicos podem ser absorvidos por 
vias oral, respiratória e dérmica, enquanto o uso indevido desses equipamentos pode, inclusive, ser uma potencial fonte de contaminação (BOHNER et al., 2013).

Após identificar como se dá a aquisição e aplicação de agrotóxicos por parte dos respondentes, resolveu-se questioná-los sobre como ocorre o descarte das embalagens, especialmente, se seguindo as orientações das Leis Federais 9974/2000 e 12.305/2010, que preconizam a prática da responsabilidade compartilhada, fazendo com que os usuários devolvam as embalagens aos estabelecimentos comerciais, onde apenas $7,5 \%$ dos agricultores promovem a logística reversa, conforme observado na Figura 6.

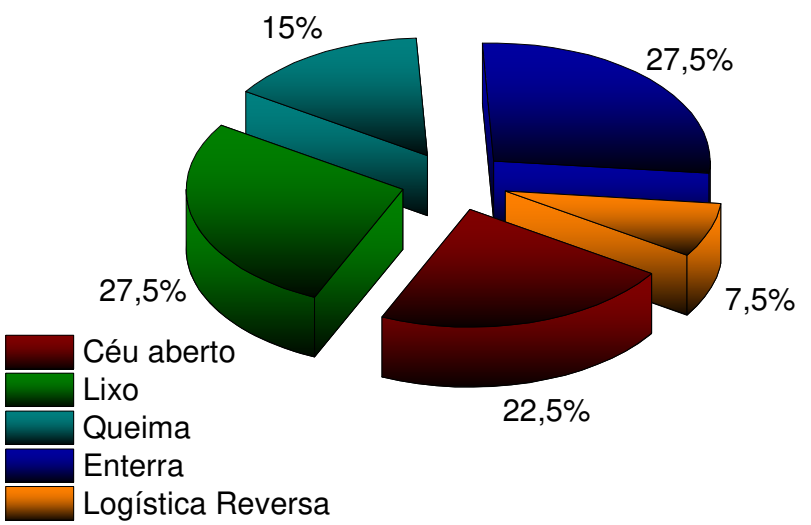

FIGURA 6: Formas de descarte das embalagens de agrotóxicos realizadas pelos agricultores de Jaguaruana - CE, Brasil.

Fonte: os autores.

No Brasil, desde 2002, há o Sistema Campo Limpo, para fomentar a logística reversa das embalagens de agrotóxicos, com 74 postos e 80 centrais de recebimentos instalados no país, sendo que, no Ceará, há apenas um posto, para o recolhimento de, situado em Ubajara, na região da lbiapaba, distante cerca de 500 $\mathrm{km}$ de Jaguaruana.

Além de investigar qual seria a destinação final das embalagens de agrotóxicos - constatando $92,5 \%$ de inadequabilidade quanto ao descarte - foi imperioso aferir se os entrevistados conheciam a Lei Federal $n^{\circ}$ 9974/2000, cujos resultados revelam que $85,1 \%$ desconhecem esse arcabouço legal.

A Lei Federal 9.974/2000 determina a responsabilidade de devolução das embalagens vazias aos usuários de defensivos agrícolas, aos revendedores e aos fabricantes, criando assim, um ciclo de logística reversa e exigindo que suas orientações fossem executadas por todos de forma integrada, implicando penalidades previstas na lei de crimes ambientais no caso de seu descumprimento. O fato de desconhecer a legislação, de adquirir agroquímicos em locais não autorizados, bem como a maior utilização sem EPls e descartar as embalagens de maneira equivocadas, são indícios da precariedade assistência técnica, constatando-se que $80,5 \%$ afirmam ser desassistidos desse serviço. 
No Ceará, a assistência técnica é promovida pela Empresa de Extensão Rural do Ceará (EMATERCE), cujo acesso a esse serviço é fulcral para o acesso ao conhecimento, assim como também o é a presença dos agricultores nos eventos promovidos pela extensão rural, sendo protagonistas e corresponsáveis (SILVA, 2014; SOBRINHO; MOTA, 2016).

A carência educacional e informativa é um dos principais problemas quanto ao uso abusivo dos agrotóxicos, segundo Bohner et al. (2013), juntamente com a frequente disseminação de informações por técnicos da indústria química, fiscalização débil, políticas de incentivo atrelada ao consumo e falta de estímulo para considerar externalidades, podendo convergir para o uso indiscriminado, causando, inclusive, a leviana sensação de que não ser viável produzir sem a utilização desses insumos químicos.

Diante de tantas irregularidades, é possível concordar com Frota et al. (2015) sobre a existência de prevalência de interesses econômicos no ciclo da utilização de agrotóxicos, uma vez que desde 1997 o Governo do Estado isenta a cobrança de ICMS, IPI, PIS/Pasep e Cofins desses produtos, afirmando que a desoneração repercute em menores custos de produção.

Pode-se aventar que este estímulo tributário proporciona externalidades e grandes custos sociais, assumidos por toda população, mediante possíveis gastos públicos com recuperação de áreas contaminadas, tratamento de intoxicações, afastamentos e aposentadoria por invalidez de trabalhadores rurais, e, até mesmo, óbito decorrente dessa prática, pondo em xeque o discurso do uso seguro, estampados nos manuais técnicos (ABREU, ALONZO, 2014).

\section{CONCLUSÃO}

Constata-se indícios de reprodutibilidade da agricultura convencional na agricultura familiar, haja vista utilização de insumos, como os agrotóxicos, em vez de defensivos naturais.

Porém, o fato dessa reprodutibilidade ocorrer sem considerar o postulado nos marcos legais - como a forma de adquirir agrotóxicos, quem os deve manipular e como descartar seus vasilhames, que possuem disciplinas jurídicas próprias converge para um estado de alerta, pois os manipuladores podem ser vitimados por algum agravo decorrente do uso indiscriminado, bem como, no intuito de maximizar produção e lucro, podem acabar por contaminar o meio, logo promovendo externalidades.

Assenta-se, portanto, que, ao ausentar-se da responsabilidade de fornecer assistência técnica devida à aplicação de agroquímicos por pequenos produtores, o Estado se torna leniente e põe a reboque a qualidade de vida desses indivíduos e do meio onde vive, em prol de interesses econômicos.

\section{REFERÊNCIAS}

ABREU, P. H. B.; ALONZO, H. G. A. Trabalho rural e riscos à saúde: uma revisão sobre o "uso seguro" de agrotóxicos no Brasil. Ciência \& saúde coletiva, Rio de Janeiro, v. 19, n.10, p. 4197-4208, 2014. Disponível em: < http://dx.doi.org/10.1590/1413-812320141910.09342014.>. DOI: 10.1590/1413812320141910.09342014. Acesso em: 14/05/ 2017.

ALMEIDA, J. (Org). A modernização da agricultura e os eixos temáticos. Porto Alegre: Editora da UFRGS, 2011. 
AQUINO, A. M.; ASSIS, R. L. Agroecologia: Princípios e Técnicas para uma Agricultura Orgânica Sustentável. 2a Edição, Brasília: Embrapa Informação Tecnológica, 2012.

BOHNER, T. O. L; VARGAS, L. P.; LIMA, F. A. X.; NISHIJIMA, T. ; WIZNIEWSKY, J. G. . Reflexões sobre os efeitos dos agrotóxicos no meio ambiente e na saúde humana: uma análise sobre a conscientização dos agricultores de Chapecó, SC. Educação Ambiental em Ação, v. 46, p. 1-18, 2014. Disponível em: < http://www.revistaea.org/artigo.php?idartigo=1730 >. Acesso em: 21/03/2017.

BRASIL. Decreto no 4.074, de 4 de janeiro de 2002. Dispõe sobre a pesquisa, a experimentação, a produção, a embalagem e rotulagem, o transporte, o armazenamento, a comercialização, a propaganda comercial, a utilização, a importação, a exportação, o destino final dos resíduos e embalagens, o registro, a classificação, o controle, a inspeção e a fiscalização de agrotóxicos, seus componentes e afins, e dá outras providências. Brasília. Disponível em: < http://www.planalto.gov.br/ccivil_03/decreto/2002/d4074.htm > Acesso em 14/06/2017.

BRASIL. Lei no 11.326, de 24 de julho de 2006, estabelece as diretrizes para a formulação da Política Nacional da Agricultura Familiar e Empreendimentos Familiares Rurais. Diário Oficial \{da\} República Federativa do Brasil. Brasília, DF 25 de julho de 2006. Disponível em: < http://www.planalto.gov.br/ccivil_03/_ato20042006/2006/lei/l11326.htm >. Acesso em 7/5/2017.

. Lei $\mathbf{n}^{\circ} \mathbf{9 . 9 7 4}$, de 6 de junho de 2000. Altera a Lei no 7.802 de 11 de julho de 1989, que dispõe sobre a pesquisa, a experimentação, a produção, a embalagem e rotulagem, o transporte, o armazenamento, a comercialização, a propaganda comercial, a utilização, a importação, a exportação, o destino final dos resíduos e embalagens, o registro, a classificação, o controle, a inspeção e a fiscalização de agrotóxicos, seus componentes e afins, e dá outras providências. Disponível em: < http://www.planalto.gov.br/ccivil_03/leis/L9974.htm >. Acesso em 13/06/2017.

CAJAIBA, R. L.; SANTOS, E. M. ; FISTAROL, R. ; ALVES FILHO, J. ; SILVA, W. B.. Perfil dos Agricultores do Município de Uruará-PA quanto ao uso dos agrotóxicos. Enciclopédia Biosfera, v. 11, p. 1479-1492, 2015. Disponível em: < http://www.conhecer.org.br/enciclop/2015b/agrarias/Perfil\%20dos\%20agricultores.pd f >. Acesso em: 12/06/2017.

CARNEIRO, F. F.; RIGOTTO, R. M.; AUGUSTO, L. G. S.; FRIEDRICH, K.; B, A.C. Dossiê ABRASCO: Um alerta sobre os impactos dos Agrotóxicos na Saúde. 1. ed. Rio de Janeiro: EPSJV, 2015. v. 1. 624p.

FROTA, D. R. S.; ROLDAN, V. P. S.; CABRAL, A. C. A.; SANTOS, S. M.; PESSOA, M. N. M. Barreiras ao desenvolvimento sustentável do agronegócio: a situação da logística reversa de embalagens de produtos agrotóxicos no estado do Ceará, Brasil. Revista Gestão \& Sustentabilidade Ambiental, v. 4, p. 68-109, 2015. Disponível em: $\quad<$ http://dx.doi.org/10.19177/rgsa.v4e2201568-104.>. DOI: 10.19177/rgsa.v4e2201568-104. Acesso em: 27 set. 2017. 
GRISA, C; SCHNEIDER, S. Três gerações de políticas públicas para a agricultura familiar e formas de interação entre sociedade e estado no Brasil. Revista de Economia e Sociologia Rural. Revista Economia e Sociologia Rural. V.52 supl.1 Brasília 2014. Disponível em: < http://dx.doi.org/10.1590/S010320032014000600007 >. DOI: 10.1590/S0103-20032014000600007. Acesso em: $14 / 08 / 2017$.

LEFF, E. Agroecologia e saber ambiental. Porto Alegre, v.3, n.1, jan./mar. 2002

MAIA, A. G.; BUAINAIN A. M. O novo mapa da população rural brasileira, Confins [Online], 25 | 2015, posto online no dia 19 Novembro 2015, consultado o 27 Dezembro 2016. Disponível em: < http://dx.doi.org/10.4000confins.10548 > URL; DOI : 10.4000/confins.10548. Acesso em: 21/05/2017.

PLEIN, C. Capitalismo, agricultura familiar e mercantilização. Informe Gepec, Toledo, v. 14, n. 2, p. 96-111, jul./dez. 2010. Disponível em: < http://erevista.unioeste.br/index.php/gepec/article/view/4008/3807 >. Acesso em 21/05/2017

PLEIN, C; FILIPPI. E.E. REDES, Capitalismo, agricultura familiar e mercados. Revista do Desenvolvimento Regional, Santa Cruz do Sul, v. 16, n. 3, p.98-121, set/dez 2011. Disponível em: < https://online.unisc.br/seer/index.php/redes/article/view/1545/1965 >. Acesso em: 12/07/2017.

SANTOS, M. N. R.; KONESKI, A. L. S.; SOUZA, F. H.; AMARAL, V. S. Diagnóstico da percepção ambiental de moradores da região de agronegócio no semiárido do RN-Brasil: impactos dos agrotóxicos ao meio ambiente. Educação Ambiental em Ação, 2013. Disponível em: < http://www.revistaea.org/pf.php?idartigo=1476 >. Acesso em: 04/04/2017.

SILVA, D. A.. A produção alternativa no assentamento Sul Bonito/ Itaquiraí/MS: o caso do grupo de agroecologia terra viva. Revista Eletrônica da Associação dos Geógrafos Brasileiros, Seção Três Lagoas, v. 20, p. 103-125, 2014. Disponível em: < http://seer.ufms.br/index.php/RevAGB/article/view/461 >. Acesso em: 30/03/2017.

SILVA, E. F.; PANIZ, V. M. V.; LASTE, G.; TORRES, I. L. S. Prevalência de Morbidade e Sintomas em Idosos: Um Estudo Comparativo Entre Zonas Rural e Urbana. Ciência \& Saúde Coletiva, Rio de Janeiro. V.18, oㅡ 4, 2013. Disponível em: $<$ http://dx.doi.org/10.1590/S1413-81232013000400016>. DOI: 10.1590/S141381232013000400016. Acesso em: 13/06/2017.

SILVA, F. M.; ANDRADE SOBRINHO, L. G.; COELHO, D.C.; FERREIRA, P. M. L.; AZEVEDO, P. B.. Percepção de risco no uso de agrotóxicos em cinco comunidades rurais no município de Pombal-PB. Revista Verde de Agroecologia e Desenvolvimento Sustentável, v. 9, p. 001-010, 2014. Disponível em: < http://www.gvaa.com.br/revista/index.php/RVADS/article/view/3179/2693 >. Acesso em: 30/06/2017.

SOBRINHO, R.S.; MOTA, E. F. Diagnóstico do Conhecimento de Agricultores de Palmeira em Beberibe-CE sobre o controle microbiológico. Educação Ambiental 
em Ação, v. 55, p. 1-8, 2016. Disponível em: < http://www.revistaea.org/pf.php?idartigo=2276 >. Acesso em: 23/01/2017.

SOCOLOSKI, A..; GRZEBIELUCKAS, C. ; NASCIMENTO, A. R. C. ; SANTOS, J. S. C. ; MALDONADO, T. V. Uso de agrotóxicos na produção de hortifrúti: um estudo em uma propriedade da agricultura familiar. Educação Ambiental em Ação, v. 57, Ano XV, p. 1-10, 2016. Disponível em: http://www.revistaea.org/artigo.php?idartigo=2405 >. Acesso em: 14/05/2017.

SOUSA, J. A.; FEITOSA, H. O.; CARVALHO, C. M.; PEREIRA, C. F.; FEITOSA, S. O.; SILVA, S. L. Percepção dos Produtores Rurais Quanto ao Uso de Agrotóxicos. Revista Brasileira de Agricultura Irrigada, Fortaleza, v.10, n 5, 2016. Disponível em: < http://dx.doi.org/ 10.7127/rbai.v10n500484 >. DOI: 10.7127/rbai.v10n500484. Acesso em: 02/07/2017.

VASCONCELOS, M.V.; FREITAS, C.F.; SILVEIRA, C.A. Caracterização do uso de agrotóxicos entre trabalhadores rurais. Saúde (Santa Maria), v. 40, n. 2, p.87-96, 2014.

VITAL, A. F. M.; LEITE, P. K. S.; SILVA, C. G.; FERREIRA, R. C. C.; FARIAS, J. R. M. A Policultura como Estratégia de Potencialização para a Flora Apícola no Cariri Paraibano. Caderno Verde de Agroecologia e Desenvolvimento Sustentável, Pombal, v.06, ํㅜ 1, 2016. 